\title{
CUARENTA POEMAS INÉDITOS DE JUAN JOSÉ DOMENCHINA ${ }^{1}$
}

La publicación de obras que su autor no dio a la estampa entraña siempre riesgos y exige, como es sabido, especiales precauciones. Entre estas, no son las más irrelevantes las de orden moral: el hallazgo de inéditos crea al filólogo un conflicto entre su compromiso con la verdad histórica y el respeto al criterio del escritor, imperativos que lo obligan por igual pero que pueden resultar inconciliables. El dilema es viejo -tanto, cuando menos, como la decisión de los amigos de Virgilio en favor de la publicación póstuma de la Eneida contra la voluntad expresa de este, según la noticia transmitida por la tradición--, y probablemente insoluble. Cuando en 1995 editamos la Obra poética completa de Juan José Domenchina (Madrid, 1898-México, D. F., 1959) dejamos fuera deliberadamente sus poemas póstumos y el corpus de inéditos que hoy, al cabo de un decenio, recogemos aquí (sólo en un escueto apéndice quisimos en aquella ocasión asomarnos a la trastienda del poeta $)^{2}$. Entonces, como ahora, se trataba de mantener las jerarquías establecidas por el autor. Cuidadoso en extremo, Domenchina publicó numerosos poemas, escribió muchos más y tuvo vínculos editoriales durante toda su vida; nada hace pensar que los versos que

${ }^{1}$ La autora agradece a Antonio Carreira las observaciones con que ha contribuido a mejorar este trabajo.

${ }^{2}$ Juan José Domenchina, Olra poética, ed. e introd. A. de Paz, pres. Emilio Miró, Castalia-Comunidad de Madrid, Madrid, 1995, 2 ts.: 388 y 452 pp. Designada con las siglas $O P$ en este artículo; las referencias a poemas éditos del autor remiten a la numeración que llevan en ella. 
dejó inéditos no hubieran podido ver la luz, de haber sido su deseo. La calidad de los no difundidos que han llegado a nuestras manos -otros, como el primer poemario escrito en su adolescencia, fueron destruidos por Domenchina- no permite sin embargo, salvo excepciones palmarias, conjeturar que nos hallemos ante meros esbozos. Más bien habrá que suponer que, en unos casos, Domenchina no creería oportuno incluirlos en el cuerpo de ninguno de sus libros, lo que unido a su conocida prevención a divulgar su poesía en revistas los abocaría al limbo; en otros, tales obras habrán constituido recreos de su soledosa expatriación, sin mayores pretensiones.

Reunimos aquí las composiciones sueltas más acabadas que hemos podido espigar entre sus papeles. Son, cuantitativa y cualitativamente, suficientes para constituir un volumen nutrido y sin desniveles, no exento además de unidad formal y de fondo. Casi todas proceden del legado domenchiniano depositado en la Biblioteca Nacional de Madrid; dos de ellas, excepcionalmente, fueron localizadas en la residencia madrileña de la viuda del poeta, Ernestina de Champourcin, y en la mexicana Capilla Alfonsina (infra, núms. 24 y 38, respectivamente). Abarcan etapas dispares de su producción, aunque la mayoría corresponde a la madurez alcanzada tras la guerra civil española. No todos los poemas están datados, por lo que en nuestra transcripción adoptamos un orden alfabético de primeros versos. Los más antiguos con fecha conocida son "Y se alegra el viento frío" (núm. 39) -cuya génesis, según el autógrafo, se remonta al temprano 1922, año de las Poesías escogidas (Ciclo de mocedad. 1916-1921) - y "Vereda -lombriz de aventuras-" (núm. 34), de la época de sus audacias vanguardistas (1929); los más tardíos, "Tú - mi otro yo de veras, mi efectivo" (núm. 30) y "¿Vuela la pluma, o la vuela...?" (núm. 36), se sitúan en octubre de 1957, dos años antes de la muerte de Domenchina, si bien algún otro, como el núm. 4 ("Apolo, falso Dios, tañe su lira"), pudiera ser posterior a esa fecha.

Básicamente, los textos ratifican al Domenchina conocido. La mejor poesía domenchiniana consiste, como sabemos, en la exploración minuciosa de unos pocos metros, motivos y registros en un lenguaje conceptuoso: a esa monotonía debe el poeta sus mayores logros y el aire de coherencia y severa armonía que posee su obra. Tales leitmotive se nos aparecen, sin excepciones notables, en estos nuevos poemas: entre las estrofas, el soneto, la décima y el romance -las más características, por ese 
orden, del autor-; en cuanto a la invención, aquellas imágenes que expresan, o bien la aniquilación del individuo por obra del destierro - tema fundamental de su poesía- tanto en el plano vital como en el metapoético, o bien su contrapunto idealizado; entre los modos, la nostalgia, el erotismo, la comunión con la naturaleza, la reflexión intelectual, la admonición y la sátira. Pero los poemas muestran también alguna vía menos frecuentada por Domenchina, como el recurso a la seguidilla en el núm. 5 o al.juguete cancioneril en el séptimo.

La selección que ofrecemos no agota los materiales existentes: por encima de la exhaustividad ha primado el rigor de dar sólo poemas completos o con aspecto de serlo, excluyendo aquellos que por su evidente carácter fragmentario o por sus dificultades extremas de lectura nos hubieran obligado a dejar lagunas $^{3}$. La endiablada letra de Domenchina no contribuye precisamente a redimirlo del olvido que lo sume, y es causa principal de la escasa fiabilidad que posee la mayor parte de las ediciones realizadas de su poesía póstuma.

1. Abril llega con su luz. Breve romance sin fechar, conservado en autógrafo en el ms. 22.267 de la Biblioteca Nacional de Madrid (BNM). Su inspiración es semejante a la de la décima "(Abril madrileño)" de Exul umbra $(O P, 610)$ y a la de los sonetos de $L a$ sombra desterrada, "Evocación de abril" ( $O P, 654)$ y "Abril" ( $O P$, 655) -estos dos últimos, de febrero de 1950. Por su concisión. y no sólo por el asunto, hace pensar asimismo en tales formas métricas, favoritas, como hemos señalado, del autor. El romance posee cierta tradición en su poesía - piénsese, sin ir más lejos, en la última serie de Destierro (1942), en Nueve sonetos y tres romances (1952) o en el romancero sin fecha de Preciada, la Pisa Bien-; lo novedoso en este caso es su carácter epigramático.

El original presenta tres versos tachados entre el segundo y el tercero, con una asimetría en los paréntesis que parece indicar -junto con la rima- que el primero de los tres fue desecha-

${ }^{3}$ En uno u otro de tales supuestos se encuentran varios no exentos de interés: "A las barcas, pescadores...!", "Cuando tu poquedad se desmesura", "La ínfima voz no sube a lo infinito", "Las ramas verdes, amor", "Pero guardarme, póstumo, secreto", "Van como autómatas. Andan", todos ellos conservados en el ms. 22.267 BNM; y "Así son estos caminos" y "Trochas, atajos, caminos", aparentemente dos versiones incompletas de un mismo poema (ms. 22.261 BNM). 
do en favor del segundo: "(Si en su retoñar fecundo / ( $\mathrm{Si}$ en su retoñar, tu vida / caduca ya, se viviese!)". Por su parte, el verso octavo - "sobre los retoños verdes"- corrige una redacción anterior: "sobre la ternura verde" (la enmienda acaso se haya efectuado al desaparecer los versos que acabamos de transcribir, donde se usa la palabra retoñar). En el reverso del autógrafo existe un borrador, del que se infiere que los dos primeros versos del poema - sin correcciones- hubieron de ser la inspiración inicial, aparentemente fácil, mientras que el resto se produjo con gran esfuerzo y numerosas vacilaciones (salvo los tres versos finales, asimismo bastante limpios en el propio borrador).

Abril y su lluvia tonificante constituyen una de las imágenes arquetípicas de la poesía domenchiniana.

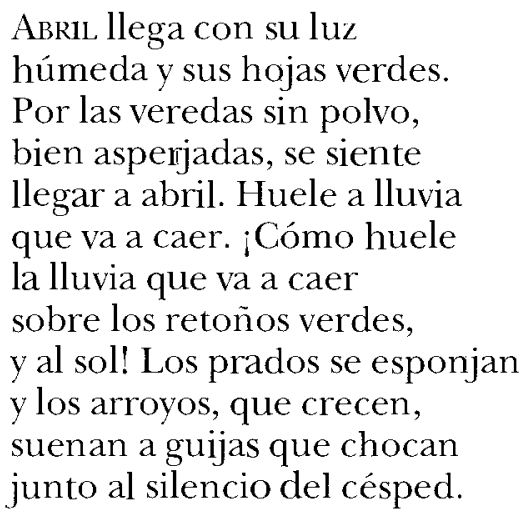

2. Alli los campos yermos y el sol: la paramera. Serventesios alejandrinos procedentes del ms. 22.267 BNM. El autógrafo, encabezado con un " 1 ", no presenta correcciones, como si hubiese sido pasado a limpio; no obstante, el texto aparece tachado por una raya vertical, en medio de la página. Aunque no lleva fecha, tal vez haya de atribuírsele la del soneto "No sé. Apenas indicio de mi dolor, tu cántico" (infra, núm. 21), que figura, numerado con un " 2 ", en la cuartilla que sigue a la que contiene esta composición. En tal caso, el poema dataría del 2 de septiembre de 1940 , lo que resulta verosímil también por razones de estilo: tanto el empleo del alejandrino y cierto preciosismo en la dicción, como la visión idealizada del páramo castellano, de corte noventayochista, corresponden en efecto a la etapa inicial del exilio de Domenchina, representada ante todo en Destierro (1942). 
Aluí los campos yermos y el sol: la paramera radiante que imponía su enjuta servidumbre. Acá, los amarillos hirsutos de la era; el pan hecho de angustia, sudor, polvo y costumbre.

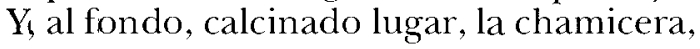
tizón de los voraces rigores de la lumbre.

¿Qué ráfaga de inquinas alzó la tolvanera que aún desdibuja el limpio diseño de la cumbre?

Allí fue, sin nostálgica pasión, la vida entera: viril orgullo, recto sentido, reciedumbre, ¡temple! Toda la vida de un ser que, aún ayer, era cabal, impostergable, y hoy, roto en muchedumbre, se acarra, cual rebaño, bajo la solanera.

3. Alta naturaleza. Sonetillo heptasilábico de dos rimas fechado el 5 de marzo de 1951. El autógrafo se encuentra en el ms. 22.267 BNM. El soneto de siete sílabas no lo practicaba Domenchina desde Margen ("Poeta joven", $O P, 321$ ), publicado en 1933, aunque, en aquella ocasión, con cinco rimas. El encabalgamiento abrupto de los vv. 11-12 (“...Caída / fatal..."), así como la última frase ("...En vida /, que ya a morirse empieza", vv. 13-14), son muy domenchinianos, y resumen la antítesis inherente al poema y al conjunto de la producción lírica del autor, hondamente platónica y senequista.

Alta natiiaieza, verdecida y erguida. Yo voy ya de vencida e inclino la cabeza.

Si tal cual vez tropieza con algo de la vida mi planta, estremecida, se encoge de extrañeza.

¿Qué grácil va y florida, con qué airosa presteza, la juventud! Caída

fatal. Esta tristeza

es despedida... En vida que ya a morirse empieza. 
4. Apolo, falso Dios, tañe su lira. Soneto conservado en un autógrafo de letra tardía (ms. $22.267 \mathrm{BNM}$ ); en el reverso aparece el borrador del poema, con múltiples tentativas.

Mantenemos la irregularidad del manuscrito en el empleo de la mayúscula en la palabra "Dios" (vv. 1 y 10). La anómala puntuación de ese v. 10 y del siguiente nos ha obligado a añdir dos comas.

Apolo, falso Dios, tañe su lira solar, augusta y exageradora. Pero oíd las palabras de la aurora en la voz que despierta y que respira.

El hombre es la verdad, él la mentira obstinada que bruñe y sobredora lo que vemos. Yel mundo, como otrora, en nuestra mente lúcida delira.

Sin hipérboles pasma la hermosura de todo. Mas el dios, desmesurante[,] con la voz impostada en su impostura[,]

emite -no le basta lo bastanteun ditirambo para la criatura que vive eternidad en el instante.

5. Ay, amor al sereno. Seguidillas del 4 de julio de 1944, día en que el poeta compuso asimismo un soneto con el que la tercera comparte asunto: "Y siempre la llanura, la llanura / de seca lentitud, que no acababa...", recogido cuatro años más tarde en la sección "Evocaciones" de Exul umbra $(O P, 588)$. Esa seguidilla final carece del heptasílabo de apertura esperable, como en una especie de anacrusis que convierte la estrofa en un doble bordón. Su segundo verso (16 del poema) ha sido corregido en el autógrafo (ms. 22.267 BNM) sobre "caminar la llanura".

No recordamos que el autor haya empleado tal estrofa en ninguna otra ocasión; quién sabe si en esta pudo inducirlo el ejemplo de Antonio Machado, poeta muy presente en su memoria y en sus escritos de los años cuarenta.

Ay, A.MOR al sereno, cómo me dueles.

([;] Toda la noche, solo, bajo la nieve!) 
Desde mi cama,

oigo, amor al relente, cómo me llamas.

$* * *$

Cuando entorna los ajos

mi soñolienta,

quiere dormir el sueño

que la desvela.

...Se me dormía

soñando en despertarse

medio dormida.

$$
* * *
$$

Ay, cómo cansa

el andar la llanura

que no se acaba.

Leguas y leguas,

por un camino a solas

que nunca llega.

6. Como penitente, miente. Décima fechada en México en abril de 1948; su autógrafo, que lleva un " 3 " en el encabezamiento, figura en el ms. 22.267 BNM. Forma serie con "Sorda lujuria, el sayal", transcrita más adelante (núm. 28), la cual a su vez va precedida de un " 2 " en el manuscrito. Pensamos que el número uno de la trilogía hubo de ser la espinela "El hábito", de $L a$ sombra desterrada $(O P, 673)$, cuyo autógrafo aparece bajo la misma signatura, con fecha del 1 de abril de 1948 y una dedicatoria reveladora: "(A una dama que, dando cumplimiento a un voto, viste hábito de parda estameña)".

Como penitente, miente tu díscola carne ufana, que, siendo tú la manzana y el cíngulo la serpiente, tu hábito es el penitente.

Si, equívoca contrición, eludes la tentación con que te palpa su furia, sólo él pena, con lujuria vil de fraile motilón. 
7. Dios et vos. Composición octosilábica con sabor trovadoresco que glosa la divisa del Marqués de Santillana ${ }^{4}$. Presenta una estructura métrica de cabeza seguida de dos tercetillos. El autógrafo (ms. 22.261 BNM) está fechado en enero de 1950.

Dios et vos

M. de Santiliant

Dıos et vos,

me llenáis del todo, y fuera

de mí vivo por los dos.

Pero cuando yo me muera

se verá que en mí no era

Dios tan grande como vos.

Largo castigo me espera.

8. En la implacable hoguera del cristiano. Soneto de contenido antisemita escrito en 1942 y conservado en el ms. 22.267 BNM en un mecanoscrito sin correcciones, con la fecha añadida a mano. Tiene resabios del léxico verboso (véase el v. 2) característico de la poesía domenchiniana anterior a la guerra, y aún presente en los primeros años del exilio.

Ev la implacable hoguera del cristiano ardió la tendinosa grey precita, no el alma membranosa del semita: servil, garruda, vil y terca mano.

De la rapacidad de lo infrahumano a la postergación que nunca grita, la ley, que no es de ley, quedó ya escrita: -No verás ni en los tuyos un hermano.

Con la codicia y el afán del oro, la primogenitura es buen terreno

para arrastrar la vida sin decoro.

${ }^{4}$ En nota al soneto de don Ínigo López de Mendoza "Buscan los enfermos sancrüarios", cuyo último verso concluye con esa expresión, escribe su editora Regula Rohland de Langbehn: "Dios e vos: es la divisa de Santillana, aplicándose «vos», según el contexto, a la Virgen o a la dama que el poeta canta, como se puede ver en otras de sus obras, por ejemplo en el decir "Desseando ver a vos"” (Marqués de Santillana, Comedieta de Ponza, sonetos, serranillas y otras obras, ed., pról. y notas R. Rohiand de Langbehn, est. prelim. Vicente Beltrán, Crítica, Barcelona, 1997, p. 236). 
Todo -el fraude, la afrenta-, todo es bueno si es útil, que hay un único tesoro: vivir a costa del sudor ajeno.

9. Eres tan estupendamente hermosa. Composición versolibrista de asunto erótico fechada el 3 de enero de 1950; su autógrafo se encuentra en el ms. 22.267 BNM. Un tratamiento similar del tema amoroso se produce en poemas tan distantes en tiempo y estética como la "Alegoría de la juventud" de La corporeidad de lo abstracto (OP, 129), las primeras "Elegías barrocas" ("Primavera de gozos" y "El estío y sus brasas", OP, 353-355 y 356-357), el "Madrigal bárbaro" de Perpetuo arraigo (OP, 622), o el póstumo "Susana y los hombres"5.

El verso quinto ha sido corregido en el manuscrito sobre otro también bastante prosaico, al que no mejora: "Cuando por fin se llega a desearte,".

ERES tan estupendamente hermosa

que el pasmo que suscitas

quiebra en añicos las palabras

y suspende el aliento.

Al mirarte -que es más que desearte-, se siente más que furia, más que amor inmediato.

Todo hirsuto

y tirante, en galope

de fiebre y de delirio,

el hombre va hacia ti para anegarse

en tu sangre que abrasa

y en tu alma, que quema.

No, no eres, no, unas ingles y unos senos

que piden amorosas

caricias lentas a lo largo

de la noche...

Exiges - porque estás al rajo vivo

bajo tu pérfida blancura

estallante- la vida

toda del hombre que te llega

sangrientamente a las entrañas.

5. J. J. Domenchina, "Susana y los hombres", PSA, 157 (1969), 53-56. 
10. Esos canes, rondadores. Romance con algún pie quebrado, que se halla en el ms. 22.267 BNM, en autógrafo y copia mecanoscrita con correcciones del autor; esta última es la versión que aquí seguimos, y a pie de página damos las variantes del manuscrito. Las rectificaciones del autógrafo permiten aventurar una hipótesis acerca de la génesis del pie quebrado en el v. 12: en primer lugar, Domenchina escribió "de repente", expresión que por la asonancia correspondía mejor al final de verso; a continuación tachó "repente", pero luego volvió a escribirlo, resultando un verso tetrasílabo. La asonancia y el significado de esa ocurrencia inicial pueden haberle sugerido la idea de dejar el verso con la mitad de sílabas. En cuanto al adverbio "siempre" del v. 38, es corrección del autógrafo sobre "vuelve". A diferencia del mecanoscrito, este pone coma al final del verso, lo que acaso sea preferible.

El poema se compuso en octubre de 1948 (presumiblemente el día 29), según indica el autógrafo. Es un desarrollo encadenado de varios motivos comunes en la poesía domenchiniana (los perros, la huella, el doble, el eco, la sombra, el muro).

\author{
Esos canes, rondadores \\ y aulladores, que nos muerden \\ con sus latidos, ventean \\ husmos o sombras de muerte. \\ Mi doble, anguloso espectro, \\ se escurre por las paredes. \\ Si mi evasión y su fuga \\ corren paralelamente, \\ no habrá nunca encrucijada \\ donde sus pasos se encuentren. \\ ¿Adónde ${ }^{6}$ llega mi sombra \\ de repente, \\ cuando se le acaba el muro \\ por donde desliza, tenue \\ réplica, la superficie \\ muda de su andar deleble?
}


¿En dónde da ${ }^{7}$ mi liviana

contrafigura de enfrente?

Yo soy yo.

Me veo y me palpo, terne.

Yo soy yo, cuerpo rotundo.

No soy ese,

lateral, adscrito, sordo

borrón, que no puede verse.

Buen remedador, repite

mis ademanes de siempre, como un simio. Simple copia y eco solo en las paredes.

Cuando se le acaba el muro, de pronto, ¿dónde se mete? ¿Dónde estrella mi perfil? ¿En qué deslices me pierde? ¿Contra qué me da de bruces? ¿En dónde a medias me tiene?

En torno, mula de noria, sin un lendel evidente, ¿cómo, si no deja huellas, tras el hosco mutis, siempre ${ }^{8}$ por lo inopinado, en juego fiel, sobre sus pasos vuelve?

:Ay ${ }^{9}$, su ir y venir me enjaula; me restriega en las paredes; parodia mis ademanes; me sigue cansinamente!

Sombra agorera, nefasto

luto de ida y vuelta, especie falsa de mi cuerpo en fuga sobre un muro liso...

¿Vete!

${ }^{7}$ ¿En dónde da] ¿Dónde cae $\Omega$

8 siempre] $\sim, \Omega$

${ }^{9}$ :Ay, ] Ay, $\Omega$ 
11. Este mundo tan exacto. Décima de contenido epistémico-moral compuesta en 1951, posiblemente el 4 de febrero, aunque la cifra del mes es dudosa en el autógrafo (ms. 22.267 BNM). Es, en todo caso, posterior a las más tardías publicadas por el autor. "Aunque ignoro" (v. 3) ha sido corregido en el original sobre "¿Sé lo que soy,"; "soledad" (v. 10), sobre "puridad". El poema tiene en el segundo verso la pausa típica de muchas espinelas domenchinianas.

\author{
EsTe mundo tan exacto \\ me da apenas su sentido. \\ Aunque ignoro lo que he sido \\ y lo que seré, me jacto \\ de verme entero en el acto

12. Feliz réplica, copia cabal... En escultura. Composición en pareados alejandrinos, sin datar; aunque la métrica y la profusión de esdrújulos son propias del Domenchina de los años veinte, la letra del autógrafo (ms. 22.267 BNM) corresponde a la posguerra. Tiene aire de irónico remedo parnasiano.

Son numerosas las enmiendas del manuscrito: en el v. 6, "siempre tensa" se corrige sobre "como sorda" (por su parte corregido sobre "en tensión"); en el 11, "espantándose" rectifica a "que ya urgido" (y esto, a su vez, a "como urgido"); en el v. 12, "engañoso" aparece sobre "arrogante"; en el 16, "mármol" corrige a "piedra".

\title{
Mármol eCUESTRE
}

Feliz réplica, copia cabal... En escultura quieta, devora espacios, entre ráfagas, pura sangre a cincel, un bruto en piedra: tasca el freno desenfrenadamente; tiene el ollar obsceno. El ímpetu, la díscola cerrilidad arranca de la indómita grupa, siempre tensa, del anca rebelde que en corcovos y botes desarzona a quien su torso, virgen de dominio, aprisiona. El pedestal broncíneo, que lo limita, es tope 
donde se aquieta, en dura tirantez, el galope

del bruto, que espantándose, crin al viento, se zafa

de un engañoso pasmo de piedra esbelta, y piafa.

Con su espuela de luz el sol, que ya declina,

acicata el ijar de la imagen equina

y el esbelto trasunto de corcel, el instable

solípedo de mármol recalcitra, indomable,

y chafa los asfódelos de aquel rincón silvestre

con el piafante garbo de su arrogancia ecuestre.

13. ¿ Has ido a buscar la canción...? Sonetillo eneasílabo de dos rimas. El autógrafo (ms. $22.267 \mathrm{BNM}$ ) lleva fecha del 19 de octubre de 1944. Presenta un par de variantes (coma al final del v. 6, y "prístino" por "genuino" en el 11) con respecto a un mecanoscrito, sin datar, conservado en el mismo sitio, que es el texto que aquí seguimos, pues tiene signos de haber sido revisado por Domenchina. El manuscrito revela asimismo que la oración interrogativa de los tercetos inicialmente se cerraba al final del primero; con posterioridad, el autor decidió prolongarla al segundo.

Por su contenido, el poema acaso se dirija a "León Felipe", antagonista implícito en alguna otra ocasión -como la "Primera elegía jubilar" $(O P, 559)$ - del sujeto que se expresa en la poesía domenchiniana; no obstante, no hay ninguna prueba externa que avale esa hipótesis.

\section{Elegía}

¿HAs ido a buscar la canción sin nombre, el anónimo acento que rompe las cuerdas del viento tirante, en su heroica tensión?

Casi tangible, el diapasón

de tu quejido macilento es grave: entrecorta el aliento, pasma y suspende el corazón.

¿Te fuiste a buscar la canción perdida, el sutil elemento genuino de la creación,

el polvo impalpable-memento desesperado en la pasión arrebatadora del viento? 
14. La luna está-jtan límpida y tan honda!-. Soneto de dos rimas fechado el 6 de mayo de 1950. Su autógrafo se halla en el ms. 22.261 (8) BNM. Es una recreación del motivo de la luna, no muy explorado en esta poesía -excepción es la décima de $L a$ sombra desterrada "La luna y los árboles" ( $O P, 677)$, cuyo original, depositado en el ms. 22.267 BNM, tiene fecha de enero del mismo año.

En el v. 4, acaso el menos logrado del poema, "más que hermosura" es enmienda del autógrafo sobre "a no sé quién,"; en el v. 5, "Descuella en el azul" sustituyó a "Está en el pleno azul".

LA luna está -jtan límpida y tan honda!en un cielo pasmoso. Resplandece atenta a su misión y no parece más que hermosura hermética y redonda.

Descuella en el azul, radiante y blonda.

Su alto pudor sin nubes se guarece en la sonrisa a medio hacer que ofrece su rictus agridulce de Gioconda.

¡Limpio recato en plenitud! La fronda trepa a su castidad intacta, crece, noche arriba, temiendo que se esconda

tras una nube... Pero permanece a toda luz y desvelada, monda, con la desnudez pura que merece.

15. La novia exangüe. Mecanoscrito con correcciones autógrafas (ms. 22.267 BNM). Ignoramos su fecha de composición, acaso coetánea de los doce "Hai-kais" incluidos en La corporeidad de lo abstracto en 1929 (OP, 138-149).

SeIS HAI-KAIS DE EPITALAMIO

(Orto de bodas)

LA novia exangüe: bajo una luna pálida, otra de sangre. 
(Tocado)

Ya no fue aquello

de desnudarse a solas

frente al espejo.

(Mimo)

Yise dormía

soñando en despertarse

medio dormida.

(Muñecas)

Como es tan niña,

le sueñan sueños rubios

en las axilas.

(Cansancio)

Por sus ojeras

se asoma a la mañana

que la despierta.

(Ducha matinal en el jardín)

Bajo la lluvia, va, casi transparentemente, desnuda...

16. Liza de amor. Se desliza. Espinela de tema erótico escrita en junio de 1948, según el autógrafo del ms. 22.267 BNM. En el v. 9 , el autor ha preferido "ven como" a una palabra ilegible (tal vez "presumen").

\section{Primera LIZA DE AMOR}

LizA de amor. Se desliza

a flor de piel la entrañable necesidad, ya palpable,

de hendir propia de tal liza. 
17. Lo que tengo no me tiene. Romance sin fecha conservado en el ms. 22.267 BNM en doble testimonio, autógrafo y mecanoscrito coincidentes. La primera de las "Variaciones" recrea el motivo del errar en vano, uno de los estilemas figurativos de la poesía domenchiniana del destierro. En la segunda, otras dos de sus imágenes más emblemáticas -el Doppelgänger y el muro- se asocian de modo inusitado, por medio de una evidente referencia metaliteraria. El autógrafo presenta algunas rectificaciones en esa segunda composición: "sorda" (v. 3) ha sido corregido sobre "piedra", y "cal" (v. 4) sobre "†vil†". En el v. 8, "poste" aparece escrito sobre una palabra ilegible; "me topé" (v. 9), sobre "te topaste". En cuanto a los vv. 10-12, primitivamente eran uno: "(cerril y expiatorio chivo)".

\section{I}

Lo Que tengo no me tiene.

Voy en vilo.

Yme aterra el no sentirme las pisadas cuando piso

un suelo que me desanda

los pasos que doy, perdidos.

II

Bellaco y zumbón, mi ciego

Lazarillo,

tras de estamparme en la sorda

cal de un muro encontradizo,

fruye el avieso arregosto

de su represalia, al filo

del ardid que me aplastó

contra el poste de mí mismo.

Ycomo ya me topé

-como un chivo

cerril y expiatorio-, en golpe

de castigo, 
con la verdad, huye el bulto

y me deja, impacto liso,

deleble, estrellado en frío.

18. Mujer de vida opulenta. Décima sin fechar que se halla, en autógrafo, en el ms. 22.267 BNM. La letra del original suscita un par de dudas de transcripción: en el v. 4, el posesivo entre cruces pudiera ser "la" (hay una ambigua rectificación en el autógrafo); en el 6, existe ante la forma verbal una negación que parece haber sido tachada. "Confundirte en" (v. 7) es corrección del autor (acaso sobre "fundirte con"); "acucia" (v. 8) fue primitivamente "urgencia".

$$
\begin{aligned}
& \text { Mujer de vida opulenta: } \\
& \text { para tu alma presurosa } \\
& \text { que te consume y acosa } \\
& \text { resulta †tu carne lenta. } \\
& \text { Vives tus sueños, a cuenta } \\
& \text { de la vida: y has logrado } \\
& \text { confundirte en lo soñado: } \\
& \text { mas la acucia sin sentido } \\
& \text { no encuentra lo que ha perdido } \\
& \text { tu vivir apresurado. }
\end{aligned}
$$

19. No díscolo, sí veloz... Composición sin datar procedente del ms. 22.267 BNM. Es una variante de la sextilla. El autógrafo, muy limpio, no presenta en este caso correcciones ni lecturas dudosas.

$$
\text { EL Si Y EL NO }
$$

$$
\begin{aligned}
& \text { No díscolo, siveloz... } \\
& \text { El siafirma y firma un pacto } \\
& \text { precoz, de urgencia, en el acto. } \\
& \text { El no recula, da coz. } \\
& \text { (Dios te libre del impacto } \\
& \text { de su retroceso atroz). }
\end{aligned}
$$

20. No, no hermética: inefable. Décima sin fecha, conservada en el ms. 22.267 BNM en doble versión: autógrafa $(\Omega)$, y mecanoscrita con correcciones autógrafas $(\beta)$, que mejora el texto del dechado, y que seguimos aquí. Este último carece de título. Precisamente el femenino del epígrafe ha debido de provocar 
la conversión en ese género de lo que primitivamente era un concepto neutro, como puede observarse en las variantes del aparato crítico. La versión mecanografiada ha optado además por el habitual comienzo lapidario de las décimas domenchinianas frente a la enumeración de aposiciones, alterando la puntuación del primer verso.

Su asunto es la especulación filosófica propia de Domenchina en este metro especialmente entre 1936 y 1942.

LA VERDAD ARDUA

No, no hermética: inefable ${ }^{10}$.
Dificil de decir, sombra
ardiente que no se nombra
con un nombre razonable.
No se nos da, pero es dable.
Si tenazmente la ${ }^{11}$ cerca,
con su lucidez de terca
esclarecedora en frío,
la voluntad, su desvío
radiante se nos acerca.

21. No sé. Apenas indicio de mi dolor, tu cántico. Soneto alejandrino con serventesios en vez de cuartetos, cuyo autógrafo (ms. 22.267 BNM) lleva un "2" al frente y fecha del 2 de septiembre de 1940 (es, pues, anterior en un par de semanas al inicio de la redacción de la "Primera elegía jubilar", $O P, 559)$. Por su disposición en el legado domenchiniano, parece formar serie con "Allí los campos yermos y el sol: la paramera", como ya se señaló (cf. supra, núm. 2). Su interés, a nuestro juicio, reside en su imperfección: en el tono convencional, todavía ajeno a la impronta que Domenchina llegará a acuñar en esa forma métrica.

En el último verso, "y angustias," es corrección del autor sobre "dibujo", y "poemas" sobre "esquemas".

No sé. Apenas indicio de mi dolor, tu cántico aturde, vocifera. No sé. Yo, taciturno, invoco lo más quedo del estertor romántico para sufrir a solas mi pena sin coturno.

10 hermética (corr. autógrafa sobre $\beta$ )] hermético $\Omega, \beta \|$ inefable.] $~, \Omega$

11 la (corr. autógrafa sobre $\beta$ ) ] lo $\Omega, \beta$ 
Donde yo llego acaso tu voluntad no alcanza.

Espero: no me cruzo de brazos en mi cruz.

Porque conozco el nombre -quizá- de tu esperanza, aguardo en las tinieblas el orto de la luz.

Me estoy, sin consentirme, sobre mi sentimiento, que no es comunicable, corriente ni efusivo.

No sé, ni quiero, henchirme de hirsutos anatemas...

Para llorar me sobra con mi conocimiento.

Para sufrir me basta sentirme firme y vivo.

Para gritar... silencios y angustias, mis poemas...

22. Noche de amor, en sombra. Desceñida. Soneto de dos rimas fechado el 20 de septiembre de 1945. El autógrafo, que lleva un "II" en el encabezamiento, forma parte del ms. 22.267 BNM. El v. 11 tuvo previamente dos redacciones sucesivas: "a que te avienes empequeñecida" y "en que te endiosas ensoberbecida!" ("en que" luego sustituido por "donde").

\section{(ENCLentro)}

Noche de amor, en sombra. Desceñida laxitud. ¡Qué fragante es la tibieza desnuda de tu cuerpo, qué belleza solo tangible tienes escondida

en tu presencia desbordante, henchida de deseo, de fiebre y de pereza! ¿Qué bien te das en la naturaleza pródiga de tus noches sin salida!

[i]Quizá no colmes nunca la medida de tu ambición, que es harta la grandeza que endiosa tu postura de caída!

¡En qué descendimiento sin bajeza tropieza con la sombra de tu vida mi enhiesto ayer que ya a acabarse empieza!

23. ¿Ojos? No los remates en "antojos". Soneto metapoético del 20 de enero de 1944. El autógrafo (ms. 22.267 BNM) presenta en el segundo verso una lectura primitiva, desechada - "termines en" pasó a ser "†consultes ał"-, junto con otras menos legi- 
bles. En el noveno, "Es del caso" ha sido corregido sobre "Es, sin duda,". Enmendamos la rima imperfecta de ese verso con el duodécimo.
¿Ojos? No los remates en antojos.
¿Labios? No los †consultes a† los sabios;
no los hagas sufrir esos agravios
fatales a los labios y a los ojos.
Si tienes hijos, di que son redrojos, mas no prolijos como los resabios del versificador que pone en labios de sus musas a rastras sus rastrojos.
Es del caso-oportuno-que no abundes en el saber no escaso del precito trovador que regüelda gerundiadas.
Has de sacarte a flote, si te hunde[s] en su procela, y, no sin apetito, te come el tiempo con pampiroladas.

24. Para una voz de aceituna. Hermosa décima en homenaje a Federico García Lorca que aparece, sin datar, en un mecanoscrito firmado por el autor al que tuvimos acceso en 1991 en el domicilio de Ernestina de Champourcin, y cuyo paradero actual desconocemos. Las referencias a El romancero gitano presentes en el poema determinan su fecha post quam, 1928. Pensamos, no obstante, que ha de ser posterior no sólo a ese año, sino también a la muerte de García Lorca en 1936, y acaso próximo en el tiempo a las "Tres décimas a Jorge Guillén" que Domenchina escribió el 9 de agosto de 1944 y que figuran en el mismo testimonio ${ }^{12}$.

Domenchina conoció a Lorca en 1932; el encuentro se produjo en una taberna madrileña y dio lugar a una simpática anécdota ${ }^{13}$. No fueron muchas más las veces que conversaron.

12 A. DE PAZ, "Juan José Domenchina: tres décimas a Jorge Guillén", Extramuros. Revista Literaria, octubre de 1996, núm. 4, 52-53.

13 Tal es el testimonio de Domenchina: "Allí, en esa taberna ["La Rambambaya"], conocí personalmente, en 1932, a García Lorca. La entrevista fue en extremo cordial, aunque yo había escrito ya algo hostil a propósito de los dengues prepósteros del poeta. «Leí sus primeros versos -me dijohace mucho y me pasmó, además, su apellido. ¡Domenchina! Cuando yo, 
Al final de su vida, Domenchina guardaba un buen recuerdo de él, pese a no contarlo entre sus poetas predilectos ${ }^{14}$. Ignoramos cuál es ese temprano texto hostil a Lorca que el autor menciona en las líneas transcritas; su reseña lorquiana más antigua que conocemos es posterior a su primer encuentro y sumamente favorable ${ }^{15}$. No parece, sin embargo, que en 1936 se hiciera eco del asesinato de quien tenía por "el lírico más considerable de toda la juventud española"16, y que apenas un par de meses atrás había suscrito en un diario madrileño dos manifiestos contra la actividad crítica de Domenchina ${ }^{17}$.

muy chiquititizo aún, jugaba al frontón con raqueta, al sacudirle a la pelota gritaba, fuera de mí, ;Domenchina!». Reí a mis anchas †de† los escapes fantásticos del genial granadino. Ponía tan to gesto, tanto ademán y una convicción tan evidente en lo que decía, que casi no era lícito contradecirle. Sin embargo, yo, no inmune a la sugestión de su contagiosa simpatía, osé puntualizar: "Mire usted, Lorca. Yo publiqué mi primer libro a los diecinueve años. Aunque usted lo leyera inmediatamente y también inmediatamente le fascinara mi apellido, como usted y yo tenemos la misma edad, ya no era usted tan chiquititizo al exclamar ¡Domenchina! o cuando le pegaba con la raqueta a la pelota...» "No le dejan a uno ni soñar-replicó con humorística pesadumbre Lorca-. ¡Yyo que me veía con pantalones cortos y chillando ¡Domenchina! en el frontón de mi casa!»” ([Madrid], ms. 22.260/3 BNM, ff. 26-27). La anécdota debió de tener alguna difusión; su primera parte la recuerda, entre otros, Joaquín Díez-Canedo, con una glosa personal: "Como poeta, [Domenchina] se oponía rotundamente a las innovaciones de la vanguardia (su gran admiración era Juan Ramón, a quien se mantuvo siempre fiel). Burlándose de él, Federico García Lorca decía que los niños de su colegio solían tirar la pelota al aire y gritar «Domenchinaa»... Con esto, claro, quería dar a entender que Domenchina no pertenecía a su generación, que era mucho más viejo; lo cual, desde luego, no era cierto, porque tenían la misma edad. Era una broma que quería hacer Federico, pero Domenchina sí le caía mal; siempre era despectivo al hablar de él" (Paloma Ulacia y James Valender, "Rte.: Joaquín Mortiz [entrevista con Joaquín Díez-Canedo]", en Rte: Joaquín Mortiz, Universidad, Guadalajara, México, 1994, p. 88).

$14 \mathrm{~J}$. J. Domenchina: "Hablé muy pocas veces con aquel gracilísimo y locuaz improvisador de lo estupendo... Pese a las diferencias radicales que nos separaron, recuerdo a Lorca, que tampoco es de mis poetas afines, con admiración y simpatía. No puedo decir lo mismo de sus aledaños" ([ensayo acéfalo, fechable hacia 1957], ms. 22.262/6 BNM, f. 41).

15 J. J. Domenchina, "Poetas españoles del 13 al 31, (I)", El Sol, 12 de marzo de 1933, p. 2.

${ }^{16} \mathrm{~J}$ J. DOMENChina, loc. cit.

17 R. Alberti, M. Altolaglirre, J. Bergamín, L. Cernuda, F. Garcia Lorca, J. Gulllén, P. Neruda y A. Serrano Plaja, "Una carta sobre crítica literaria", Heraldo de Madrid, 30 de marzo de 1936, p. 11 y "Contestación a una carta del señor Domenchina", Heraldo de Madrid, 2 de abril de 1936, p. 15. 
En 1941, ya en México, sí se refirió Domenchina a las circunstancias de la muerte de Lorca en su Antología de la poesía española contemporánea (1900-1936), donde reproduce, actualizándolo, el elogio que le dispensara en 193318. Es posible que la décima que aquí damos a conocer responda, en un plano distinto, a la misma intención de hacer justicia al poeta, completando su figura con la semblanza lírica.

RECUERDO DE LORCA

Para una voz de aceituna, un cutis aceitunado; presentimiento aceitado de olivar y noche bruna. iAy, bronce y sueño, a una luna de estaño, con aureola de sangre! Jaca sin cola ni crin, que se dirigía a donde no llegaría.

...Córdoba, lejana y sola.

25. Puesta de sol. El viento, que es livido y salobre. Soneto alejandrino del 30 de abril de 1944 -si la cifra del mes en el autógrafo (ms. 22.261 BNM) es, como creemos, un cuatro, y no un nueve como podría interpretarse. Por su ubicación en el fondo domenchiniano de la Biblioteca Nacional, se pensaría que formara parte de Poemas y fragmentos inéditos (1944-1959), pero no figura en ese libro: el ingenuo remate de su segundo terceto habrá provocado acaso su relegación. La palabra "tarabillas" aparece con uve en el manuscrito.

\section{ESTAMPA IMPRESIONISTA}

Puesta de sol. El viento, que es lívido y salobre, unta, impregna de sal y yodo. Abre su boca el puerto... Rueda un disco de cobre tras la roca de los acantilados rojos, también de cobre.

El cielo se encelaja y precipita sobre las verdes $\nmid$ tarabillast de un mar que se disloca

18 Antología de la poesía española contemporánea (1900-1936), sel., pról. y notas críticas y bio-bibliográficas J. J. Domenchina, epíl. E. Díez-Canedo, Editorial Atlante, México, 1941, pp. 330-331. 
en tendinosos surcos de mucilago y choca con el cantil la espuma de su beber salobre.

Allí, en la orilla, un mástil deshecho y una quilla rota dicen, despojos del naufragio, el poder del mar innumerable que se acerca a la orilla,

monótono, insistente, queriendo y sin querer...

Del mar innumerable que dobla la rodilla

y se tiende de espaldas igual que una mujer.

26. ¿Qué nos miente el tullido fablistán? Un azumbre. Serventesios alejandrinos. Una raya o rúbrica al final del autógrafo (ms. 22.267 BNM) parece indicar que el poema está completo; otra raya vertical, en medio de los versos, lo desestima. Aunque no lleva ningún número en el encabezamiento, figura en una tercera cuartilla del mismo tipo que las que contienen las composiciones "Allí los campos yermos y el sol: la paramera" y "No sé. Apenas indicio de mi dolor, tu cántico" (supra, núms. 2 y 21), lo que puede ser significativo para su datación (la segunda de estas se escribió, como dijimos, el 2 de septiembre de 1940). La segunda estrofa podría constituir un bosquejo de unos versos de la "Primera elegía jubilar" $(O P, 559)$, compuesta entre el 18 y el 27 del mismo mes ${ }^{19}$.

¿QUế nos miente el tullido fablistán? Un azumbre de vino pide a trueque de hurgarse la mollera y repetir el viejo dictado. Con la herrumbre de ayer dora su torpe facundia trapacera.

¡Patrañas! Ya no existe sobre la podredumbre vendida del terrazgo sino una calavera: residuo de la mente demente que hizo lumbre con su memoria, y solo ceniza de la hoguera.

27. Solo, en fin. La muchedumbre. Décima autógrafa sin fecha procedente del ms. 22.267 BNM. Aparece en el reverso del manuscrito de otra espinela, "Siempre distante y errante" $(O P, 674)$,

19 J. J. Domenchina: “¿Y ahora? Sólo existe / sobre la podredumbre del terrazgo / vendido, España triste, / un atroz mayorazgo: / el del hambre que llora sin hartazgo. // Solo una calavera / sobre el yermo: residuo de la mente, / demente y altanera, / que supo, zarza ardiente, / descarnarse y morir enteramente" ("Primera elegía jubilar", vv. 131-140). 
impresa en La sombra desterrada. Omitimos la coma que el original presenta al final del v. 2 (es costumbre del autor poner ante un inciso esa coma contraria al uso). En el 8, escribió "obscenas colisiones" sobre "wsordos† apretujones"; en el 9, ha corregido "o" sobre "y".

\author{
Solo, en fin. La muchedumbre \\ que se restriega y retoza \\ -calentándose sin lumbre- \\ con los codos, no me roza. \\ Sexo plural, su marea \\ unánime, que menea \\ olas de turbia resaca \\ en obscenas colisiones \\ furtivas, o tentaciones \\ sucias, en limpio me saca.
}

28. Sorda lujuria, el sayal. A esta décima nos hemos referido más arriba (cf. núm. 6, "Como penitente, miente"). Se halla en versión autógrafa en el ms. 22.267 BNM, con un "2" como epígrafe, según indicamos, y fecha de 1948 (que habrá de restringir a abril de ese año, mes de composición de "Miente, evidente impostura" $(O P, 673)$ y de la susodicha "Como penitente, miente", con las que es probable que forme una tríada.

En el verso tercero, "tus pechos" ha sido corregido sucesivamente sobre "tu pecho" y "tus muslos". En el cuarto, "muslos" constituye una vuelta a la lectura primitiva, tras haber sido sustituida esta por "pechos". La palabra "pues" del v. 9 se ha corregido sobre "porque"; en el 10, "hace" es enmienda sobre "ejerce".

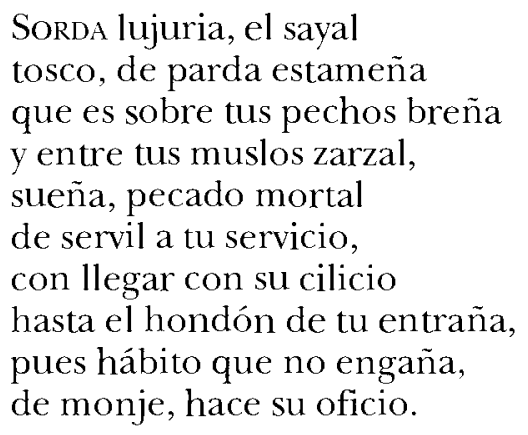

29. Tantas veces de amores requerida. Soneto diazmironiano sin fecha a una mujer de vida alegre, asunto otras veces tratado en 
esta poesía. Figura en el ms. 22.267 BNM, en autógrafo firmado por Domenchina. En él, "vehemente" (v. 2) se corrige sobre "tan fácil", a su vez corregido sobre "querida". En el v. 11, "casi" fue originariamente "como". "Y" (v. 12) se corrige sobre "Ya"; "aburre" (v. 14), sobre "cansa" (este último verso ha tenido dos lecturas anteriores sucesivas: "te aburres aunque estés entretenida" y "†... $\nmid$ de estar entretenida").

TANTAS veces de amores requerida, tan pródiga y vehemente, no sufriste nunca dejar a un hombre solo y triste, que fuiste ducha en alegrar la vida.

Pero en la vida alegre, que convida a banquetes efimeros, tperdiste† el galardón precioso que luciste: la apetencia y la carne apetecida.

Por rebasar la norma, ya salida, entrar en razón luego no pudiste. Yestás fuera de ti, casi corrida.

Y no eres, como ayer, la bienvenida, que, al no poderte dar como te diste, te aburre ya el vivir entretenida.

30. Tú-mi "otro yo" de veras, mi efectivo. Soneto de dos rimas, con consonancias frecuentes en la etapa mexicana del autor. Se conservan dos versiones distintas del poema: la que parece la primitiva (ms. 22.261 BNM, autógrafo) lleva fecha del 29 de octubre de 1957; la otra antepone un lema de san Juan de la Cruz (ms. 22.267 BNM, mecanoscrito sin fecha con ligeras correcciones autógrafas que salvan errores de mecanografia; es la que aquí damos). Afirma Laura Cao-Romero que el autor dedicó este poema a su esposa un año antes de morir, lo que ha de ser una cronología aproximada, pues el original, según hemos dicho, prueba que se escribió exactamente dos años antes de su fallecimiento ${ }^{20}$. 
Tú -mi "otro yo" de veras, mi efectivo ser- eres la verdad que estoy yo siendo desde que en mí naciste y voy viviendo, para alcanzarte el alma, cuanto vivo.

Porque tú sientes, en tu pensativo mirar y ver, lo que me vas haciendo sentir, mientras soportas el tremendo amor de mis angustias, siempre vivo.

Dios - me llevas a Dios- es tu motivo absoluto de ser. Yvoy naciendo en tu ser, de mi muerte redivivo.

Verdad entera vamos compartiendo, verdad entera -amor libre y cautivo--, aunque es de noche, con la vida ardiendo.

31. Triste alegria española. Estrofa manriqueña a modo de apunte cuyo autógrafo se halla en el ms. 22.267 BNM sin indicación de fecha. La copla de pie quebrado constituye, como es sabido, el metro de uno de los poemas más notables de Domenchina, su "Segunda elegía jubilar", de enero de 1941 (OP, 560).

Triste alegría española de Madrid al sol: plazuela y organillo.

La noche, que duerme sola con su vecindad en vela, tiene un grillo.

32. Un árbol crece. ¡Ohpura elevación! Pseudosoneto sin fecha hallado en el ms. 22.267 BNM, con un número "I" al frente, en romanos. Se trata de un mecanoscrito con correcciones autógrafas: "de este mismo" (v. 3) es una inserción manuscrita, al igual que "sus" e "y, no" (v. 6) -copulativa, esta última, donde la minúscula es discutible. El texto presenta algunas anomalías: el verso segundo obliga a una forzada dicción; en el primer terceto, la repetición del adjetivo "pobre" (v. 9 y 11) más parece torpeza que recurso intencionado. Falta además en el original la indicación 
del comienzo de la frase exclamativa con que concluye el poema; restituimos el signo de admiración de modo conjetural.

El poema recrea la leyenda órfica, con un tratamiento serio de la mitología poco usual en Domenchina (y quizá por ello, poco convincente). No sabemos si el inciso del segundo terceto ("-umbral / triste de vacilantes troncos secos-", wv. 12-13) constituirá un recuerdo deliberado de la caverna del Polifemo gongorino.

Un árbol crece. ¡Oh pura elevación!

Orfeo canta. ;Oh árbol, ya sublime al oído!

Yaunque todo enmudece, de este mismo silencio

apunta, en signo y trueque, un nuevo comenzar.

Agrúpanse las fieras del bosque, desprovisto

ya de sus abrigaños... y, no por solapada

astucia o por temor, sino solo, tan solo

por oír, en silencio, cautelosas, se acercan.

El mugido, la brama, el grito son ya pobre cosa, nada, en su pecho. Yallí, donde hay apenas

como albergue una pobre choza, o el escondite

fortuito que el instinto oscuro encuentra - umbral triste de vacilantes troncos secos-, [i]allí, improvisaste, edificaste un templo!

33. Verde y estremecida primavera. Soneto de dos rimas fechado en noviembre de 1954, mes crítico en la existencia y la poesía de Domenchina. Desde el otoño - real y metafórico-que vive el poeta, evoca la primavera aferrándose a la luz y a la esperanza. El autógrafo se encuentra en el ms. 22.261 BNM, fechado y rubricado; bajo la misma signatura figura también el poema en un calco de mecanoscrito donde aparecen, igualmente mecanografiadas, sus iniciales; este último presenta una corrección autógrafa.

El v. 5, "verde silencio verde, verde espera", es la lección definitiva tras dos previas: 1 ) "verde silencio... La verdad te espera"; y 2) "verde silencio. Y el amor espera". En el 10, "y todo su sentido" se ha corregido en el autógrafo sobre "sin fruto prohibido" (a su vez corregido sobre "y todo su sentido", que es por tanto la lectura primitiva y la final). Los dos últimos versos del poema presentan varias tentativas en el manuscrito, tachadas: 1) "Tu otoño reverdece en primavera"; 2) "(Mi otoño reverdece tent mi pradera / con palabras que a Dios han florecí- 
do[)]"; 3) "(Mi otoño reverdece. Mi pradera / está llena de Dios y de sentido)".

VERDE y estremecida primavera. La savia busca luz y es un vagido de vida. Viento verde, verde nido, verde sonoridad, verde pradera,

verde silencio verde, verde espera.

Todo tiene un vivir recién nacido y está como de un sueño suspendido.

Esperemos -callad-a que Dios quiera

que nos llegue la vida verdadera de su sazón y todo su sentido.

Ved: ya se escurre el sol por la ladera.

Ya pronto será abril lo prometido.

(Mi otoño reverdece y salen fuera los renuevos del árbol prohibido).

34. Vereda-lombriz de aventuras-. Composición en serventesios eneasílabos del 25 de enero de 1929, cuyo autógrafo Domenchina hubo de llevar consigo a México y hoy para en el ms. 22.267 BNM. Por su título, parece responder a la inspiración que dio lugar a la serie "Espejos" de El tacto fervoroso (1930), donde no tuvo cabida.

En el v. 8, "breve" es corrección del autor sobre "brusco"; entre los vv. 12 y 13 aparecen dos, tachados: "en el desenlace aventuras / son tus pisadas inseguras".

EL ESPEJO

(Atajo en curvas en la pupila del espejo)

VEREDA - lombriz de aventurasque te tuerces hacia el pinar, hay en tus humildes torturas congoja urgente de atajar. Tus revueltas están maduras como a golpes de calcañar. Todo el alivio que procuras lo cobras en breve acezar. 
Fraude piadoso, tú nos curas

de la ufanía de llegar.

Humilde lombriz de aven turas

-cuento dramático, el pinar-

acortas; suprimes. Premuras

son tus huellas. ¡Útil andar!

El bosque se hinche de venturas.

Al bosque no puedes llegar.

¡Desde mi puerta hasta las duras

guijas del pueblo! Ese es tu andar.

Aislada por las lindes puras

e inexorables del pinar.

35. Vivo sin verme, entre mil. Décima hallada en autógrafo en el ms. 22.267 BNM; en la misma caja se conserva un mecanoscrito del poema con leves correcciones autógrafas, que antepone el título "Poeta mozo", recurrente, con variaciones, en la poesía y en la prosa domenchiniana. Su fecha parece ser 1948, aunque la última cifra es dudosa en el autógrafo. En este, "en mí veis" (v. 9) ha sido corregido sobre "me ven".

De nuevo nos hallamos ante el tema por excelencia de la poesía domenchiniana: la obsesión por la pérdida de la identidad.

$$
\begin{aligned}
& \text { Vivo sin verme, entre mil } \\
& \text { ojos que me ven y veo, } \\
& \text { cuando mi solo deseo } \\
& \text { es contemplar el viril } \\
& \text { trazo que soy: mi perfil } \\
& \text { enterizo. ¿Qué postura } \\
& \text { me dará, sin impostura } \\
& \text { o deformación oblicua, } \\
& \text { lo que en mí veis, no la inicua } \\
& \text { réplica de mi apostura? }
\end{aligned}
$$

36. ¿Vuela la pluma, o la vuela...? Décima del 26 de octubre de 1957. El autógrafo se conserva en el ms. 22.261 BNM, junto con una copia mecanografiada con correcciones autógrafas, y un calco de mecanoscrito sobre el que también se han realizado enmiendas autógrafas, idénticas a las del primer mecanoscrito. El original presenta numerosas correcciones en el noveno verso; al dorso aparece el borrón, en tres fases, que permite estudiar la génesis del poema.

La composición recrea el motivo de la escritura, caro al autor, con la consabida referencia a Ícaro (recuérdese otra dé- 
cima anterior en un cuarto de siglo, "La pluma quiere volar", de Margen, $O P, 340)$.

\author{
¿Vuela la pluma, o la vuela \\ el viento? ¿Liviano oficio? \\ ¿Tal vez voluble ejercicio \\ de ingravide $z$ sin escuela? \\ Como volatín -o vela \\ andaluza - al cielo salta \\ siempre con celo y sin falta. \\ Ícaro pudo caer. \\ La pluma, no. Para ser \\ de veras ;ha de ir tan alta!
}

37. ... Y se quedará desierta. Décima del 2 de octubre de 1949 que no fue recogida en La sombra desterrada, impreso a mediados del año siguiente. Insiste en los frecuentados motivos de la voz perdida y la llanura sin límites. Figura en el ms. 22.261 (8) BNM, entre los materiales de El extrañado, en autógrafo con sendas correcciones en v. 7 ("dura" pasó a ser "oscura", para volver a la forma original) y 8 ("estante" aparece sobre una palabra ilegible, tal vez "abrasante"). Existe también un mecanoscrito del poema (ms. 22.267 BNM), sin fecha ni enmiendas manuscritas, que lee "muerta" en vez de "yerta" en el v. 5.

$$
\begin{aligned}
& \text {...Y:SE quedará desierta } \\
& \text { tu voz, hoy tan bien poblada, } \\
& \text { tan populosa. Ya nada } \\
& \text { saldrá de tu boca, abierta } \\
& \text { para siempre, pero yerta. } \\
& \text { Serás como una llanura } \\
& \text { sin límites: tierra dura } \\
& \text { y sorda, aridez estante. } \\
& \text { Serás el impresionante } \\
& \text { silencio de esa llanura. }
\end{aligned}
$$

38. ... Y te malbarató, caro Rivera. Soneto escrito en Cuernavaca durante la redacción de Pasión de sombra, que Domenchina comunica por carta a Alfonso Reyes ${ }^{2 I}$. Su fecha probable es el 5 de febrero de 1944, día en que el autor llegó a aquel lugar (del 6 es ya el

21 J. J. Domenchina: "Pero sí quiero anticiparle, lo primero que escribí al llegar a este retiro paradisíaco, o así" (carta del 15 de febrero de 1944, Capilla Alfonsina, expediente 'Juan José Domenchina”). 
soneto "Aquí tengo, Señor, la maravilla", $O P, 526$, el más antiguo compuesto en Cuernavaca que recoge Pasión de sombra).

El detonante del poema habrá sido acaso la contemplación de los murales del Palacio de Cortés en Cuernavaca, obra de Diego Rivera subvencionada por el embajador estadounidense Dwight W. Morrow ${ }^{22}$. La actividad de este en favor de la política de la "Buena vecindad" y el significado de su apellido dan pie a los conceptos de los cuartetos ${ }^{23}$. El segundo de estos supone ya una inflexión hacia lo que verdaderamente incumbe a Domenchina: su simpatía hacia Cortés por su muerte lejos de su verdadera tierra, Nueva España. Ya en otro soneto de Pasión de sombra ("Tierra de soledad, desconocida", $O P, 465$ ), escrito mes y medio antes, el autor había tratado un episodio de la conquista española de México - el suplicio de Cuauhtémoc-, con un enfoque similar: atrayéndolo al campo de su única inquietud, su tormento particular de desterrado.

...Y TR: malbarató, caro Rivera, tu buen vecino, y tu pincel experto retorció en contorsiones ese entuerto -ni mexicano ni español-de afuera...

Morrow no es circunstancia pasajera: es perenne enemigo y amo cierto que os mariguana el porvenir despierto con perfidias que os sirven de frontera.

Pintaste mal...

Aquí Cortés un día vio, presintió su muerte en tierra extraña, en duro suelo de la vieja España

22 "Fueron pintados en 1929-1930 y cubierto su costo por Dwight W. Morrow, embajador de los Estados Unidos de América... La conquista es presentada con todos sus horrores: la lucha desigual dada la superioridad de las armas y técnica guerrera; la explotación, malos tratos y crueldades, exigencia de tributos y trabajos forzados a los conquistados" (JORGE GurRía LaCroix, Hernán Cortés y Diego Rivera, Instituto de Investigaciones Históricas, México, 1971, pp. 55-56).

23 "La denominada Era de la Buena Vecindad comienza ya en la administración de Coolidge. Para muchos historiadores tal política se inicia cuando Coolidge envió como embajador a México a Dwight Morrow, hombre comprensivo yjusto" (Francisco Morales Padrón, Historia de unas relaciones difíciles [EE. UU.América española], Universidad, Sevilla, 1987, p. 180). 
con su avatar de aventurero en guerra:

se vio a solas y lejos de su tierra,

[i]de la tierra que en México tenía!

39. Y se alegra el viento frío. Autógrafo (ms. 22.267 BNM) fechado en el lapso 1922-1944 por Domenchina. Los vv. 4-10 se imprimieron en la sección "Dos canciones y un epitafio" de Exul umbra (1948) sin el blanco interestrófico y con alguna variante de puntuación $(O P, 617)$.

Y SE alegra el viento frío.

Noche de Navacerrada,

abierta sobre el camino.

Que no diga el corazón jamás su corazonada...

Súbita y equivocada voz de sangre, extravasada en un vuelco de pasión.

Que no diga el corazón jamás su corazonada...

$$
* * *
$$

Con la obsesión del deseo, se me ciñe lo macizo y apremiante de su cuerpo.

$* * *$

Pero tú, serrano esquivo, no vas a abarraganarte en las faldas de un hocino.

No tengo nada que darte, nada que valga la pena. Me quitaron la alegría $y$ he perdido mi tristeza. 
Soy una sombra, un recuerdo que se arrastra por la tierra. No tengo nada que darte, nada que valga la pena.

40. Ya que lo quieres así. Décima autógrafa del 9 de agosto de 1944, localizada en el ms. 22.267 BNM. Aparte de la lectura dudosa que marcamos entre cruces, el original presenta algunas enmiendas: en el v. 1, primitivamente ponía "quisiste" en vez de "quieres"; en el 3, "te" se corrige sobre "me" y "otro" sobre "como"; en el 4, "no" sobre "me". En el quinto, "vano" ha pasado a ser "eso", y luego "algo"; en el v. 6, "El" se corrige sobre "Un".

Al igual que sucede en otras décimas de Domenchina-como en la núm. 36, arriba transcrita, o en varias de Exul umbra $(O P, 598,599,602,606,614)$, por limitarnos al período mexicano-, la reflexión metapoética es el objeto de esta.

Ya que lo quieres así, no haya día sin poema.

Yo te doy otro problema:

los días que no perdí

en algo que no escribí.

El poema sin esquema

previo y sin estratagema

tarteroł, que conseguí

en el silencio que $\nmid$ di $†$

como pausas de tu lema. 
